\title{
Motivational Differences between Monolinguals and Bilinguals in the Context of English as a Foreign Language: A Case Study on the Xinjiang Uyghur Autonomous Region
}

\author{
Rayhangül Ahåt \\ College of Foreign Languages, Xinjiang University, Ürümqi, China; \\ Department of Foreign Language Acquisition and Education, Kyoto University, Kyoto, Japan
}

\begin{abstract}
Learner motivation is considered one of the most important individual variables that affect learners' achievement in the educational domain. Utilizing the Expectancy-Value Theory (EVT) of achievement motivation proposed by Eccles and her collaborators, this study focuses on the motivational differences between minority and majority learners ${ }^{1}$ in the context of English as a foreign language in Xinjiang where minority students learn English (L3) in Chinese (L2). This study further explores how much the minority learners' L2 proficiency level influences their motivation in learning L3. Three hundred and seventy-one students from one of the top universities in Xinjiang voluntarily answered a questionnaire and forty of them were interviewed. Results of both quantitative and qualitative analysis showed that minority learners were more motivated than majority learners in learning English. The minority students' L2 proficiency level was found to have an influence on their interest in learning L3 at the low-intermediate level. From these findings, the present study discusses the importance of systematic English education and the medium of $\mathrm{L3}$ instruction for the minority as well as the implications for improving the motivation of the majority EFL learners in Xinjiang.
\end{abstract}

Index Terms - motivation, minority, majority, $\mathrm{L} 2$ and $\mathrm{L3}$, language policy and planning, bilingual education

\section{INTRODUCTION}

Language services several interests of people--economic, developmental, scientific and cultural (Pattanayak, 1990). Thus language policy and planning (LPP) must be understood in relation to macro imperatives such as sociopolitical, historical, and socioeconomical factors at the local and national level (Kaplan, 2011; Kaplan \& Baldauf, 1997). As a leading developing country in the world, China places a high value on the role of LPP in developing the country and integrating its 55 ethnically minority nations into mainstream society. With the wide spread use of English as an international language, rapid economic development, and the growing status of China in the world, LPP for minority groups has become more complex and challenging, as does the process of teaching Chinese as a national language and English as an international language to a minority population of over 120 million. In China, the notion of bilingual education (双语教育) has a different meaning for the majority and the minority. For the majority (Han ethnicity), bilingual education refers to Chinese-English education designed to cultivate talented citizens who can survive the competitive global economy and make contributions to the modernization of the country. As Baker (2006) and Hu (2008) claim, it also differs from most forms of bilingual education for the minority language students that are typically denoted by the term in international contexts, because there are no power relations between Chinese and English, and nor has it the goal of assimilation into mainstream society. For the minority, bilingual education refers to Chinese mother tongue education designed to cultivate minorities and integrate them into mainstream society with a national identity within China and ethnic identity within their homeland (Feng, 2009). This study focuses on investigating minority students' responses to Chinese-English bilingual education and LPP. This research explores the EFL motivational differences between the majority and the minority in the context of the Xinjiang Uyghur Autonomous Region where Uyghur make up the majority.

Geographical location and population distribution of the Xinjiang Uyghur Autonomous Region

The Xinjiang Uyghur Autonomous Region is located in northwestern China, with a total area of 1,6640,001 square kilometers, which makes up one sixth of China's total territory. It is the largest provincial-level administrative region in the country. To the north, east, and west, Xinjiang shares its 5600 kilometers of borders with eight countries: Russia, Mongolia, Kazakhstan, Kyrgyzstan, Tajikistan, Pakistan, India and Afghanistan. The region's location makes it a crucial part of the historical "Silk Road," as the strategic channel by which Eastern Asia connects to Central Asia, the

\footnotetext{
${ }^{1}$ The term majority learners refer to Han ethnicity and minority refers to majority Uyghurs and other non-Han ethnicities in Xinjiang.
} 
Middle East, and Europe. Therefore, the Autonomous Region occupies a vital strategic position of international importance.

According to the Xinjiang Uyghur Autonomous Region Bureau of Statistics in 2010, there are 13 ethnic minorities in Xinjiang with the total population of over 21 million. Minorities account for twelve million, $60.4 \%$ of the total population. Over nine million Uyghur make up $45 \%$ of the total population of Xinjiang and $0.79 \%$ of the total population of China. Over eight million Han make up $41 \%$ of total population of Xinjiang and $91.9 \%$ of the total population of China. Kazaks make up 7\% and the other nine ethnic minorities account for 7.5\% of the total population of Xinjiang. Based on historic migration, the total population of Xinjiang has grown from 2.1 million in 1900 to nearly 20 million in 2000 (Cao, 2010). The Han population has grown from nearly 6\% in 1953 to over $41 \%$ at present.

\section{Education}

\section{Bilingual education}

Chinese and Uyghur languages are the two official languages of the Xinjiang Uyghur Autonomous Region since the establishment of People's Republic of China (PRC), and they play different roles and have different status. Regarding the goal of minority education, Ma (2007) and Eric (2007) assert that minority education in Xinjiang followed the Stalinist philosophy of language that emphasized the notion of a single and unified socialist state. Thus minority LPP was of a top-down nature. Under this policy, although a minority population could account for the majority in a specific region, the same minority LPP was administered by the central government throughout the country even though regional governments had some limited autonomy. The present educational system for the minority in Xinjiang follows the same pattern: mother tongue-Chinese (mainly Uyghur) bilingual education, and it has been introduced to almost all minority schools whether they are ready or not. The mode of this bilingual education differs from region to region as a result of varying levels of economic development and the population distribution of the each ethnicity in each region.

The recently issued draft plan by the Educational Bureau of the Xinjiang Uyghur Autonomous Region (2012, August) once again emphasizes the importance of bilingual education for the minority. According to this plan, from 2015 to 2020, minority children should receive two years' Chinese education before they enter elementary school, so that they can easily transfer from native language instruction to second language instruction from elementary school on. According to Ma (2009), in 2000, there were 461 minority-Han joint schools in total; in 2004, the number was 656; in 2005 , it increased to 707 . However, these schools only make up nearly $13 \%$ of the total minority schools. In 2004 , there were 5451 primary schools in Xinjiang of which 3777 (70.3\%) were minority language schools, and 3297 (60.5\%) were Uyghur language schools; there were 1965 Secondary schools of which 971 (49.4\%) were minority language schools, and $726(36.9 \%)$ were Uyghur language schools. Uyghur language primary schools make up 87.3\%, and Uyghur language middle schools make up 74.8\%. According to Zhou (2004), the percentage of ethnic minority students receiving education in their native language medium schools represents somewhere between $65 \%-70 \%$, and in southern Xinjiang as high as $96 \%$ of the total. Those who do not attend native language medium schools went to Han schools or a variety of other schooling where the medium of instruction is Chinese. These include Minkaohan students (民考汉) who go to Chinese language medium schools, special classes set up for ethnic minorities outside Xinjiang (内地新疆 班), special classes for ethnic minorities in Chinese language medium schools in Han majority areas in Xinjiang (疆内 民族班), mixed Uyghur-Han schools (民汉合班)and experimental Chinese language medium based classes in Uyghur schools (实验班, 宏志班, 尖子班).

2. English education

Foreign language education is not new for minorities in Xinjiang. Right after the foundation of People's Republic of China (PRC), when language policy was tolerant of minorities, Uyghur and other non-Han minority students in Xinjiang had the freedom to choose either Chinese or Russian as a second language, and these two languages had the same status (Masataka. 2008; Zhou, 2004). If we compare the following two policy documents specifically mentioning foreign language education for minorities in the region, we are able to comprehend the policy changes in minority language education. The first was issued in May 1950 by the then provincial government. The document entitled "Directive on Reforming the Current Education System" required students whose native language was Chinese to opt for either an ethnic minority language or Russian, and minority students to opt for Chinese or Russian (Xinjiang Weiwuer Zizhiqu Difangzhi Bianzuan Weiyuanhui, 2000 <cited in Sunuodula \& Feng, 2011: p262). The second document issued by the Xinjiang Uyghur Autonomous Region Education Bureau on December $15^{\text {th }} 1977$ explicitly recognized two different systems in foreign language education for the minority and the majority (cited in Sunuodula \& Feng, 2011:p 263). The document entitled "Curriculum Plan for Ten-year Full-time Primary and secondary schools in the Xinjiang Uyghur Autonomous Region (draft plan)" stipulated that:

"ethnic minority schools provide Chinese as the compulsory second language school subject from Year 3 of primary school until the end of secondary school education; no foreign language courses are to be provided. Han and Hui primary schools should generally teach an ethnic minority language as a school subject. At the junior secondary school, two thirds of the Han and Hui schools should offer ethnic minority language courses and the other third should offer foreign language courses. At the senior secondary school level, all Han and Hui schools should offer foreign language curriculum; no ethnic minority language curriculum is to be offered". 
From the above documents, it can be inferred that after the Cultural Revolution, no foreign languages were offered for minorities in Xinjiang. Instead Chinese education was strengthened and its domination in school curricula was increased from four hours from junior high school to four hours from elementary grade three after the Cultural Revolution (Masataka, 2008). Chinese was perceived to be the only language capable of enhancing minority education in an era of rapid economic development, modernization and globalization (Ma, 2007 \& 2009). However, the situation is changing rapidly as may be seen in a recent Regional-level document promulgated by the Xinjiang government on promotion of 'bilingual education' (the Ministry of Education $<\mathrm{MoE}>, 2004$ ). Moreover, an increasing number of Uyghur pupils in mixed communities or cities attend Chinese medium schools or Chinese-Uyghur mixed schools from childhood (Tsung \& Cruickshank, 2009). This context brings a new challenge to bilingual education for minorities. The new environment for minority education was acknowledged in guidelines set out by the MOE (2001a, 2001b \& 2007) which emphasized the need to vigorously promote the study of English at schools attended by Chinese speakers. Minority students or those who go to Han schools or other kinds of Chinese medium schools mentioned previously have the privilege of learning English either from Junior high school or from Senior high school. However, these students make up a small percentage (民考汉、 $5.8 \%$; 内地新疆班, less than one percent; 实验班, 6.6\%) of minority students (Ma, 2009).

Although documents issued by the MoE call for English provision from primary school Grade Three (MoE, 2001a; 2001b), English provision for the minority is simply kept out of the system, and the opportunity to learn English in minority schools in the entire region is simply not available. LPP for the majority is further in accordance with the concept that "Educational institutions reproduce social hierarchies that advantage those who have access to the ways and norms of the dominant group and that marginalize those who do not" (Lee \& Anderson, 2009). Recently some minority schools in more Han populated areas such as Ürümqi (Han ethnicity makes up over 75\%), Karamay (Han ethnicity makes up over 76\%) and Shihezi (Han ethnicity makes up over 95\%) have begun to have English classes. However, these schools make up a very small proportion.

After the issuance of the MoE's directives (2001a, b and 2007), at some tertiary schools, minority students have formally begun to learn English as an L3 in L2. Regardless of their English level they study English from the beginning for one or two school years (This largely depends on schools and field of study. Art students usually learn for one year, and science students for two years). There is not any explicit or implicit LPP on their English education from either from central or local government. When discussing implementation of the MoE's guidelines for introducing English as a compulsory subject from primary school, scholars have (Lam, 2007b; Feng, 2005 and Yang, 2005) addressed the challenges in promoting English education that language educators face in ethnic minority areas. These not only concern external factors such as poverty, inadequate teacher supply and excessive school work, but also minority students' ethnic identity, personal development and academic performance in L1 and L2, and their low motivation for learning L3. In this context, Hu (2005) notes similar problems faced by Han students in the process of EFL learning.

An attitude can simply be a state of mind, a 'disposition to react favorably or unfavorably to a class of object', and values are developed and adapted in the process of socialization from parents, peers and social institutions such as schools (Ager, 2001). The beliefs, attitudes and discourse of a given society are reflected in educational LPP, specifically in language planning at schools (Cenaz, 2009). At the same time schools have influence on society, and in the case of Xinjiang, knowledge of English affects minority learners' personal development, social attitudes and status, identity and career opportunities. In addition to these factors, minority English education is important for the security, stability and development of the region that has a long border with foreign countries and greater economic potential for tourism and trade. In the case of foreign language learning, motivation, one of the key individual variables, is an influential factor that reflects learners' beliefs about learning a given language required or privileged by a certain LPP. In the case of Xinjiang, the present mother tongue-Chinese bilingual education and the medium of L3 instruction for the minority may play a critical role in their EFL motivation that reflects the MoE's LPP that vigorously promotes English education in schools where majority students attend. Understanding the EFL motivation of minority learners in comparison to the majority can help actors in the field of LPP make sound policy and assist instructors in designing a curriculum that meets students' needs while promoting their learning of the target language at the same time. Thus the goal of this study is to explore and understand the EFL motivation of two different cultural groups within same social context but under different LPP system. EVT of achievement motivation is selected as the theoretical base of this study, because (1) in the case of minority learners, the task value "cost" suits them best because of the L3 medium of instruction; (2) in the case the majority, many studies using other motivational theories were conducted to explore EFL motivation in other regions of China, however, they revealed conflicting results and failed to explain EFL motivation; (3) in the authors knowledge, to date there are no empirical studies on the EFL education of culturally, historically and linguistically distinctive minority and majority groups in a multilingual and multicultural context like Xinjiang. In this context, this study aims to answering the following research questions.

RQ1. Do minority EFL learners have the same motivation as majority EFL learners?

RQ2. Does minority students' L2 proficiency have an influence on their L3 motivation?

\section{LITERATURE REVIEW}


The conception of the term motivation differs among theorists and researchers from different fields. In the EVT model of achievement motivation, Eccles et al. (2004) defined learner motivation as the combination of individual's expectancy for success and their value beliefs in a task. They define expectancy as the individuals' beliefs about how well they will do on an upcoming task; this depends on learner confidence in their intellectual abilities and on their estimation of the task difficulty, and relates to a sense of competence, self-efficacy and locus of control. In selfdetermination theory, competence refers to the feeling that one has the capacity to effectively carry out an action. Feelings of competence are promoted by communicating expectations that are challenging without being overwhelming. Deci, Ryan, and their colleagues $(1985,1995,2000)$ include the need for competence as one of the three basic needs of human psychology and discussed how this need is a major reason for people to seek out optimal and challenging activities. Bandura $(1977,1986,1997)$ also mentioned the importance of expectancy in his self-efficacy theory. He defines self-efficacy as one's judgment of ability to complete a task successfully. This factor can affect effort through expectations for success, and efficacy expectations determine how much effort learners will expend and how long they will persist at a given task. Learners' attributions of success or failure to internal or external factors such as effort, ability, and task difficulty also influence their motivation (Graham, 1988a; Eccles \& Wigfield, 2002; Tremblay \& Gardner, 1995) and the attributions learners make about their past experience have an impact on their expectancy in pursuing or avoiding their goals (Weiner, 1985). Expectancy for success is incorporated in the above-mentioned motivational theory as an important element.

Regarding task values, Eccles et al. (2004) defines these as the qualities of different tasks and how those qualities influence individual's desire to complete the task. They grouped individual value beliefs toward a task into four types. Intrinsic value: the enjoyment or emotional incentives a person receives from completing the task and his or her subjective interest in the task; this is closely linked to intrinsic motivation in self-determination theory. Decy \& Ryan $(1985,2002)$ also define this concept as the enjoyment one feels while performing an inherently interesting activity, as in the case of a learner who experiences a spontaneous sense of satisfaction in mastering linguistic and communicative challenges and elaborating on her capacities in the new language. Utility value: the individual's future goals for undertaking the task such as achieving required credit at school, gaining a prestigious job in society and so on. This component of subjective task values is very similar to the external regulation of extrinsic motivation in selfdetermination theory in which the cause of an action is out of the learners' own control. Attainment value: the personal importance of doing well on a given task. This refers to the needs and personal values that an activity fulfills and includes the following subcomponents: (a) conceptions of personality and capabilities, (b) long-range goals and plans, (c) ideal images of what one should like to be, and (d) schema regarding the proper roles of men and women (Eccles, 1994). Thus, in this sense, attainment value closely links to the more internalized form of external regulation in selfdetermination theory and the ideal L2 self in the L2 motivational system Cost: negative aspects of engaging in a task, such as performance anxiety, task difficulty, fear of failure, the time spent on a given task and so on. Choices are influenced by both negative and positive task characteristics and all choices are assumed to have costs associated with them (Wigfield el at. 2004), because learners will loose opportunities that result from making one choice rather than another. In this sense, task difficulty plays an important role in learners' choice of a task and engagement in it.

Competence beliefs and higher levels of value motivate students academically (Pintrich, 2003). Based on the EVT model of achievement motivation, learners' academic engagement is best predicted by the combination of students' expectancy, ability, beliefs and task values both directly and indirectly (Wigfield \& Eccles, 2000). Research has provided support that ability beliefs are positively related to educational expectancy (Bandura, Barbaranelli, Caprara, \& Pastorelli, 2001; Trusty, 2000) and task values (Bong, 2001; Chouinard, Karsenti, \& Roy, 2007; Deci \& Ryan, 1985; Eccles \& Wigfield, 1995). However, these beliefs and values vary from culture to culture and change in the process of learners' socialization in a certain culture (Eccles et al, 2004 \& 2008).

\section{METHODOLOGY}

\section{Quantitative}

Participants: Participants in this study are university students from two different ethnic groups who are linguistically and culturally different. The students from the minority group have a language of the SOV pattern as their mother tongue and students from the majority speak Chinese as their mother tongue that belongs to the SVO pattern. Their mean age is 21 . The learners from the minority group began to learn English formally half a year before the study was conducted, and many of them learned English previously at private language centers. Among this group, most are Uyghurs including a small number of Kazaks (the total number of Kazak students is eight); all have taken the Chinese Proficiency Test (HSK) $)^{2}$. Their HSK levels range from band six to band eight. The sample size of the study is 371 , there are 175 participants from the minority group and 196 from the majority.

Research Instrument: The research instrument (see appendix) utilized in this study is composed of two parts: a personal information sheet, and a six point Likert scale questionnaire where learners chose a response from strongly

\footnotetext{
${ }^{2}$ The Chinese Proficiency Test (HSK) is China's national standardized test designed and developed by the HSK Center of Beijing Language and Culture University to assess the Chinese language proficiency of non-native speakers (including foreigners, overseas Chinese and students from Chinese national minorities).
} 
agree to strongly disagree. This is designed to explore learner motivation. The personal information sheet is used to establish the minority students' L2 proficiency level, previous English learning experience, age and major. The questionnaire on learner motivation is based on the Motivational Scale proposed by Wigfield \& Eccles (1994; 2000), later modified by Ohki (2009), and was distributed during English class time by the author's colleagues after some modifications. Although the instrument has been tested in EFL contexts, a pilot study was conducted to further confirm its reliability and validity.

Medium of Instruction and duration: At colleges in Xinjiang, the required medium of instruction for the minority students is Chinese, and even if they have English teachers from the same ethnic group, English classes are basically conducted in Chinese and English, and sometimes include a little Uyghur ${ }^{3}$ if the teachers are Uyghur. For students from the majority group, English classes are conducted in Chinese and English even if they have teachers from the minority group, because they don't learn the languages of minorities. English courses for the minority usually start either from the second or third college year, and it is now a compulsory school subject ${ }^{4}$. They have regular English classes normally five hours a week for one or two school years ${ }^{5}$. Learners from the majority group also have five hour long English classes held every week for two school years. Teaching materials are also different. A unified textbook ${ }^{6}$ is used for majority learners. They have a two-hour listening class per week. Minority students use textbooks for beginners. Teaching methods for both groups are focused on vocabulary explanation and grammar translation.

\section{RESULTS}

After investigating the internal consistency, Pearson's correlation analysis is conducted to explore the coefficients of each motivational variable. Results are shown in table 1.

TABLE 1

PEARSON'S CORRELATIONS OF EACH MOTIVATIONAL VARIABLE

\begin{tabular}{|c|c|c|c|c|c|}
\hline & Expectancy & Attainment & Intrinsic & Utility & Cost \\
\hline Expectancy & $\ldots$ & $.37 * *$ & $.67 * *$ & $.16^{* *}$ & $-.36 * *$ \\
\hline Attainment & & - & $.54 * *$ & $.62 * *$ & $-.16^{* *}$ \\
\hline Intrinsic & & & $=$ & $.36 * *$ & $-44 * *$ \\
\hline Utility & & & & - & -.03 \\
\hline
\end{tabular}

As Table 1 reveals, all motivational variables except for cost positively correlated with each other and negatively correlate with cost. Utility value also negatively correlated with cost, but this finding is not statistically significant. This result demonstrates the high utility value given to English in Chinese society. These results further support Nunan's (2003) idea of the impact of English as a global language on educational policies and practices in China when knowledge of English enhances promotional prospects in the job marketplace.

A T-test was conducted to compare the overall motivational differences between the two groups. Table 2 reveals the results.

TABLE 2

MEAN, SD AND THE RESULTS OF T-TEST

\begin{tabular}{|l|l|l|l|}
\hline Group & Mean & SD & t-value \\
\hline minority & 51.04 & 16.79 & \multirow{2}{*}{} \\
\cline { 1 - 4 } majority & 39.30 & 33.59 & $4.14 * *$ \\
\hline
\end{tabular}

The t-test results in Table 2 show that the overall motivation of the minority group was significantly higher than the motivation of the majority group $(\mathrm{t}=4.14)$.

In order to investigate each motivational variable of the minority EFL learners in comparison to the majority group, a further t-test was conducted. Results are shown in table 3.

\footnotetext{
${ }^{3}$ Uyghur is the mother tongue of the Uyghurs, a minority group. According to bilingual education polices for minorities in Xinjiang, minorities should have classes in Chinese at tertiary level.

4 English education for minority students changes frequently and varies among faculties

${ }^{5}$ An hour is 50 minutes; one school year consists of two semesters, and one semester is four months.

${ }^{6}$ Unified textbook refers to the New Horizon College English published by Shanghai Foreign Language Press. This textbook is used in others parts of China as an English textbook for college students. It is composed of listening, intensive reading, extensive reading and fast reading activities.
} 
TABLE 3

THE RESULTS OF T-TESTS

\begin{tabular}{|c|c|c|c|c|c|}
\hline & \multicolumn{2}{|c|}{ Minority } & \multicolumn{2}{|c|}{ Majority } & \multirow[b]{2}{*}{ t-value } \\
\hline & Mean & SD & Mean & SD & \\
\hline expectancy & 4.76 & .81 & 3.61 & 1.06 & $11.54 * * *$ \\
\hline attainment & 4.86 & .90 & 4.80 & 1.03 & .55 \\
\hline intrinsic & 4.60 & 1.02 & 3.87 & 1.24 & $5.84 * * *$ \\
\hline utility & 4.96 & .76 & 5.16 & .78 & $-2.46^{*}$ \\
\hline cost & 3.92 & .73 & 4.06 & .93 & -1.60 \\
\hline
\end{tabular}

As shown in table 3, statistically significant differences were revealed between expectancy for success $(\mathrm{t}=11.54)$, intrinsic value $(t=5.89)$ and utility value $(t=-2.46)$ between the two groups. Expectancy for success and intrinsic value of the minority group were higher than that of the majority group; when it came to utility value, the majority group held significant higher utility value than the minority group. Based on the t-test results, the author further conducted ANOVA to explore the relationship between each motivational variable in order to better understand the motivational differences between the two groups. Table 4 reveals the results.

TABLE 4

THE RESULTS OF ANOVA

\begin{tabular}{|l|l|}
\hline minority & utility $\geq$ attainment $\geq$ expectancy $>*$ intrinsic $>* * * \operatorname{cost}$ \\
\hline majority & utility $>* * *$ attainment $>* * * \operatorname{cost} \geq$ intrinsic $>* *$ expectancy \\
\hline & Notice: $* \mathrm{p}<.05 \quad * * \mathrm{p}<.01 \quad * * * \mathrm{p}<.001$ \\
\hline
\end{tabular}

Table 4 reveals that both groups attach a high utility and attainment value to English, with intrinsic value the same for both groups. However, in the case of majority learners, no significant differences occurred between intrinsic value and cost as it did in the minority group. This group held higher expectancy and think English less costly than the majority even if they learn it in L2. These results are further explored at a later stage of this discussion.

Based on the correlation analysis results shown in table 1, there is a strong negative correlation between intrinsic value and cost. Based on ANOVA results shown in table 4, there is a strong relation between intrinsic value and cost in the minority group. This indicates that the medium of L3 instruction (the cost of learning L3 in L2) most likely influences the minority learners' interest in L3. In this context, research question two was designed to explore the motivational differences of the minority students with different L2 proficiencies.

The students are divided into three groups according to their L2 proficiency level: group A (low-intermediate level), group B (intermediate level), and group C (high-intermediate level), and to address the second research question, oneway ANOVA is conducted to explore motivational differences among the three groups. Table 5 shows the results.

TABLE 5

MEAN, SD AND THE RESULT OF ANOVA

\begin{tabular}{|l|l|l|l|l|l|l|l|}
\hline \multirow{2}{*}{} & Group A & \multicolumn{7}{l}{ Group B } & Group C & \\
\cline { 2 - 9 } & Mean & SD & Mean & SD & Mean & SD & Sig \\
\hline expectancy & 4.55 & .58 & 4.67 & .68 & 4.75 & .81 & .48 \\
\hline attainment & 4.33 & .66 & 4.52 & .57 & 4.44 & .63 & .40 \\
\hline intrinsic & 4.14 & 1.30 & 4.723 & .85 & 4.62 & 1.03 & $.042^{*}$ \\
\hline utility & 4.75 & .68 & 4.96 & .75 & 5.13 & .81 & .29 \\
\hline cost & 3.80 & .57 & 3.66 & .64 & 3.72 & .67 & .64 \\
\hline
\end{tabular}

The results in Table 5 show a significant difference in only intrinsic value between group A and group B. This indicates that even within the intermediate level, minority learners' L2 proficiency is largely different. This result is further examined at a later stage of this discussion.

\section{Qualitative}

Interviews

To extract the reasons of students' learning English specifically, 40 students were interviewed for a more in-depth exploration into what the questionnaire responses might mean. Of this group, 20 were majority and 20 were minority students.

\section{A. The Majority Students}

Student 1. Learning English helps us know and understand the cultures and habits of others. It is convenient if I know English when I am traveling abroad.

Student 2. I like learning English and I am interested in western culture. I learn English to get a better job and to go abroad.

Student 3. I like American films and I think its cool to speak in English. I also study it to pass the English exam.

Student 4. I like western music and films. They are more interesting than ours.

Student 5. English enriches our life and helps self-development. It is an international language.

Student 6. I am interested in western culture and now English is an international language. 
Student 7. English is a global language and it helps us survive the challenges of the competitive society.

Student 8. I am learning English to go abroad in the future and to find a better job. English is an international language, if you don't know English, you will be out.

Student 9. I am studying English to go abroad. I also like English films.

Student 10. You have to study English to pass CET band four and for further study. Learning a language means you have more advantages over others.

Student 11. I learn English to get a batter job and to have a better social position.

Student 12. English is an international language. It helps us develop ourselves.

Student 13. English is very difficult and I don't like at all, but I keep learning it because it is useful in communication with others.

Student 14. English is an international language. So I am learning it to catch up with the modern development and technology.

Student 15. I learn English just for the exam. I think it should be an elective class, not compulsory.

Student 16. I just learn English to get enough credits for graduation. I think we need to learn more practical things than bookish English.

Student 17. English is an important subject for graduation and further study but it takes too much time and effort.

Student 18. I study English for exams and for further study in order to get a better job in the future.

Student 19. English is an international language and very important. It helps us communicate with people from different cultures and we can learn about modern technology and development with it.

Student 20. You can communicate with different people around the world if you know English. It also helps you understand the advanced culture of others.

The qualitative part of this study further proves the quantitative part of it. From the above extract, it can be inferred that the EFL motivation of the majority students is mostly based on its instrumentality. Seven of the interviewees said that English was an international language and it helped them learn about modern technology. Five of the students said that they learnt English to find better jobs or have a better social position. This means that the students are already aware of the fact that English is the international language of science, it has a high utility value in the job market and in the process of social promotion in the Chinese society. Five of the interviewees mentioned that they were interested in western culture, English films and music. This suggests that students are exposed to foreign cultures through modern information technologies such as the Internet both directly and indirectly. Three of the students said that they felt English was difficult and took too much time and effort. They also suggested that it shouldn't be compulsory. This finding emphasizes the fact that majority students felt less successful although they spent more time and started learning English earlier than minority students.

\section{B. The Minority Students.}

Student 1. English is an international language. My major and my future have a strong link with it. I think knowing a language can help one become knowledgeable.

Student 2. English is an international language. We are able to know more advanced techniques if we know English. English helps us become more knowledgeable.

Student 3. I like English. I think it plays an important role in developing myself, exploring my potential and making progress in my future.

Student 4. I am learning English for further study and going abroad. I think its easy.

Student 5. I am learning English for further study, getting a job and traveling abroad.

Student 6. Learning English is a social expectation. The job market requires you to know English.

Student 7. I am learning English for further study, getting a better job and studying abroad.

Student 8 . I want to study abroad and I am very interest in international affairs.

Student 9. I am learning English to develop myself, get a better job and study abroad.

Student 10. I love learning English. I study it for further study and a better job.

Student 11. I am learning English in order to communicate with the people from other countries and to get a job.

Student 12. I am learning English to gain more knowledge and advanced techniques, to broaden my worldview and to compete with the Han.

Student 13. I am learning English to catch up with social developments, find a better job and go abroad.

Student 14. Learning English is an interesting thing. It enriches my life. Most importantly, it is an international language. I want to go abroad in the future.

Student 15. English is an international language. It helps us improve our cross-cultural communication ability and helps us better understand the cultural differences between them and us.

Student 16. I am interested in learning English. I want to study abroad if possible. Anyway, if I know English well, I won't be in trouble in the future.

Student 17. I am learning English to catch up with social developments, to pass the exam, to find a job and to improve my language skill.

Student 18. I think English is very important in my life. If I know English, I can find a job easily.

Student 19. I like learning foreign languages. I am learning English to go abroad and find a better job. 
Student 20. I found English interesting after I learn it. It helps us broaden our knowledge and get a better job.

Minority students have more reasons than the majority for learning English. Nine of the interviewees said that they learnt English either to find jobs or to study abroad. This indicates that minority students face more difficulties than the majority in finding jobs and they are better able to compete with majority learners in the competitive job market if they know English. Among them one clearly stated that he learnt English to broaden his knowledge, to gain modern technology and to compete with the Han. Seven students said that English was the international language and they learnt it to catch up with modern technology, to gain more knowledge and to communicate with people from foreign countries. This indicates they viewed English as important in developing themselves and widely recognized it as the lingua franca of international communication. They are motivated to learn English for career and academic development and to act as a global citizen. Three students stated that they like learning English. Unlike their majority counter parts, they said English was interesting and easy to learn. This finding is most likely the effect of their L2 learning experience and geographical location. As noted in the introduction, minority students have language-learning experience and Xinjiang has a long border helping exposing them to foreign cultures and languages either directly or indirectly.

\section{Discussion}

RQ1. Do minority EFL learners have the same motivation as majority EFL learners?

In answer to research question one, t-test results showed that the minority learners held higher expectancy and intrinsic value than the majority learners. These findings are in disagreement with the study results reported by Shaaban et al. (2000) and Ibrahemi (2003), in which no motivational differences were found between monolinguals and bilinguals. They are also inconsistent with those of Jiang et al. (2007) who found that the minority learners were less motivated than the majority learners. In their study, the minority participants Hui speak Chinese as their mother tongue. The results also have contradicted the findings reported by Ojijed (2010) who found the Mongolian minority students were instrumentally motivated. Based on utility value, the majority learners in this study held higher utility value than the minority learners. None of the findings of the above studies are in line with the findings of the present study. The findings regarding research question one will be further discussed in terms of their relationship to each motivational variable in the EVT model of achievement motivation below.

Expectancy for success: Considering the present educational system and the minority students' native language, their higher expectations for success in L3 in comparison with the majority can be explained by the operation of the following two factors: language learning experience and language typology.

In terms of the present educational system as mentioned in the methodology, minority students in Xinjiang have language-learning experience. As a result of the bilingual educational system, two languages: Uyghur and Chinese are utilized in the minority students' daily communication. For example: in formal situations at school they have Chinese medium instruction, after school they communicate in their mother tongue with people from their own ethnic group. Moreover, in internet communication, they use both Uyghur and Chinese, and Chinese Pinyin simultaneously in different amounts. Both English and Uyghur are stress-based, and Uyghur has a larger consonant and vowel inventory than Chinese does, making most English sounds easier for minority students to learn. Moreover, unlike the native language of the majority, a large number of technical words and expressions are directly borrowed from English to the minority students' native language. For example: computer $\rightarrow$ compyoter; telephone $\rightarrow$ telefun; television $\rightarrow$ telivizor, and internet $\rightarrow$ internet.

The main source of the majority students' lower expectation can be attributed to the evaluation system and social comparison to peers. For example, most majority students feel less successful at the expense of long duration and more effort in learning English compared with other school subjects. Even though they learn English for about ten years, most of them fail national tests such as the CET and PETS ${ }^{7}$. This negative feedback probably results in low expectancy of learning English. Another possible explanation for their lower expectations is social comparison. Most majority students tend to compare their English proficiency, especially oral skills, with minority students' in terms of the amount of effort and the time they invest. This social comparison might negatively influence their expectations.

Attainment Value: The increasingly high status of English in Chinese society leads both minority and majority students to believe in its importance. The source of these perceptions mainly comes from both social and individual expectations. According to recent documents released by the MoE (2001,No.2; 2007, No.2), universities should strengthen and create conditions for Chinese-English bilingual teaching in order to raise teaching standards, accommodate internationalization, globalization and modernization. Various academic exams such as exams for Master or Doctorial Degrees test their English proficiency, and in a competitive job market some businesses require English competency. As Wigfield (2010) noted the task of learning EFL was important when students viewed it as central to their own sense of themselves. For minority students, mastering English brings them a sense of security in a competitive job market and symbolic power in comparison with the majority. These social issues lead both groups to believe that English plays an important role in both future career and personal development.

${ }^{7}$ CET is the abbreviation of College English Test and PETS is the abbreviation of Public English Test System organized by the MoE to test English proficiency. 
Intrinsic value: The higher intrinsic value of minority EFL learners' motivation can be explained by the following: interest in knowing about the world and the influence of native culture. As citizens of China, minority students in Xinjiang are very interested in knowing about world events. If they acquire English, they are able to better comprehend the cultures of both Islamic and non-Islamic countries. This feeling of curiosity likely enhances their interest. $90 \%$ of the minority students in this study are from border areas of Xinjiang like Ghulja, Kashgar and Hotan. These areas are more influenced by the culture of neighboring countries compared with more Han populated areas such as Shihezi, Ürümqi, Karamay. The geographical location of ethnic minorities in Xinjiang most probably enhances their interest in foreign cultures and languages for different purposes. They learn English, Turkish and Russian for academic and trade goals, and Arabic for religious reasoms. As Renninger et al. \& Hidi (2002) claimed, minority students' high interest in learning English may be supported through their interaction with their social environment.

Utility Value: Values are promoted in society, and students react to these values differently according to the intensity of their social needs (Viau, 2004). Judging from the hierarchy of motivational variables, utility value ranked first in both groups. This is most probably the result of rapid economic development and a series of recent events such as entering the WTO, hosting the Asian Cup, and the Shanghai Fair in China. These events may lead students to perceive the market value of English in a competitive job market.

Both groups place a high value on the utility of English, however, based on this quantitative study, utility value in the majority group is significantly higher than in the minority. These findings support the results of previous studies (Gao, Zhao, Chen \& Zhou, 2004; Warden \& Lin, 2000; Chen, Warden \& Chang, 2005) which show that majority EFL learners in China are instrumentally motivated. This trend can be attributed to the advantages of social mobility for majority students inside and outside of China. In comparison with minority students, the majority are able to find jobs more easily in coastal regions or in other more developed areas of China where there are more opportunities to use English.

Cost: Minority students ranked cost last among the five variables while the majority group ranked it third. This finding can be attributed to differences in the school curriculum. Minority students in Xinjiang have less test anxiety compared with the majority because they are exempted from the CET. As mentioned previously, recently released documents by the MoE state that if possible, majority students should have science instruction in English: the minority students are free from these requirements. Therefore, majority students are forced to spend more time learning English than other courses in order to meet the English language requirement set by the MoE.

RQ2. Does the L2 proficiency of minority students have influence on their L3 motivation?

Research question two aims to explore whether the minority students' L2 proficiency has an influence on their motivation in learning L3. ANOVA results showed significant differences between the intrinsic value of groups A and B. This result indicates that even though minority students achieve the required L2 level set by the Xinjiang educational Bureau theoretically, this does not imply that they are ready to have instruction in L2. In this case, the minority learners' limited L2 proficiency negatively influences their interest in learning L3. As Yang (2005) claims, the first and foremost thing they have to do is to reach the required L2 proficiency level set by colleges and universities. Otherwise they need to spend extra time and money to graduate on time. In this regard, the cost of achieving the required level of L2 proficiency decreases their interest in learning L3. Another explanation for this result may be that in order to protect their self-esteem students with lower L2 proficiency would likely lower the intrinsic value of English in comparison with group B and C whose L2 proficiency is higher than themselves.

\section{CONCLUSION AND LIMITATIONS}

\section{Educational Implications and limitations for the majority}

The results of this study show that among the motivational variables expectancy for success and intrinsic value in the majority group were relatively lower than in the minority group. Judging from the correlation results, expectancy for success and intrinsic value show the highest positive correlation, and cost shows the highest negative correlation with expectancy for success and intrinsic value. This implies that if majority learners' intrinsic value increases, their expectancy for success increases and cost decreases as well. Therefore, assisting majority students to develop interest in English is an effective means to improve their motivation in EFL learning. All over China everybody knows the expression ' $y a b a$ yingyu'; the literal meaning of this expression is that students can read and write in English, but cannot speak it fluently. As Viau (2000) claimed, helping majority students develop good study habits and learning strategies may be helpful to enhance their interest. Designing activities that assist them in developing communicative skills or activities that are close to the target culture beneficial means to increase their interest. Methodology is another important determinant of learner motivation in formal learning situations. In Xinjiang, EFL teaching follows the traditional method of grammar explanation and English classes usually involve discussions of classroom routines such as 'Have you recited the text?, Please open your books...; today's grammar is....' .As Dörnyei (1994:281; 2001:123) suggests EFL teachers can help students develop interest by introducing novel unexpected topics that incite their curiosity, and also support them by providing information about the target culture. Thus in order to enhance the motivation of the majority EFL learners, the influence of teaching materials, classroom interaction and teaching methodology needs to be further studied.

Educational implications and limitations for the minority students 
For minority EFL learners, the primary goals of this study are two-fold. First, by discovering the motivational differences between the minority and the majority in EFL learning, this study emphasizes the importance of continuous systematic English provision for the minority. Second, by investigating the influence of the minority learners' L2 proficiency on their L3 motivation, it provides suggestions for improvements in current L3 instruction. From the study results, it can be claimed that minority students are willing to learn English. Thus implementation of a systematic and well-planned English education system not only helps minority students to survive in a global society, it also avoids further exacerbating their marginalization. Moreover, such a system enhances integration into mainstream society, and narrows the educational and economic gaps between the minority and majority. In terms of L3 instruction, the school system that requires the minority EFL learners to have L3 instruction in L2 leave the majority of the minority students whose L2 proficiency is not well enough in a disadvantages position, and in the end leads to educational gap not only between inter groups, but also among intra groups. Therefore, the medium of L3 instruction should be taken into consideration in the case of the students whose L2 proficiency is lower than band six. In this case, the role of L1 in relation to L2 and L3 should not be neglected in the process of the minority students English acquisition. Regarding the minority students' L2 proficiency, most minority students at college have already reached the L2 proficiency level set by their schools, therefore this study was unable to explore the L3 motivation of learners whose L2 level is below band six or above band eight. These differences need to be further explored. This study employed a questionnaire based on the cognitive component of the EVT model. Because of the complexity of the educational system in which the majority students learn English in L1 and the minority students learn it in L2, a questionnaire related to the social components of motivation is needed to better understand the minority learners' EFL motivation. There is also a need to explore the influence of the minority students' L2 motivation on their L3 motivation.

\section{APPENDIX}

1. I am mastering what I have learnt.

2. I am more competent in English than my classmates.

3. I think I will get good grades in my next English test.

4. I think I can achieve my goal of successfully learning English.

5. I think I can master English.

6. It is important for me to have good grades in English.

7. I want to do well in my English study.

8. It is worth learning to master English.

9. It is important for me to be able to use English completely in all situations.

10. It is a pleasure to learn English.

11. I like learning English.

12. The acquisition of English is useful for my plans after leaving university.

13. What I have learnt in the English course will be useful for my future profession.

14. English is difficult for me.

15. To get good grades in English, I have to work hard.

16. To master English I give up other pleasures.

17. Learning English is a burden (painful) in several ways.

18. It is important to be someone who can see things from the prospective of English speakers.

\section{REFERENCES}

[1] Ager. D (2001). Motivation in language Planning and Language Policy. Multilingual Matters.

[2] Bandura. A. (1977). Self-efficacy: Toward a unifying theory of behavioral change. Psychological Review, 84, 191-215.

[3] Bandura, A. (1986). Social foundations of thought and action: A social cognitive theory. Englewood Cliffs, NJ: Prentice Hall.

[4] Baker, C. (2006). Foundations of bilingual education and bilingualism (4th ed). Multilingual Matters.

[5] Bernat, E. (2004). Investigating Vietnamese ESL learners' beliefs about language learning. English Australia Journal, 21, 4054.

[6] Biggs, J. B. (1992). Why and how do Hong Kong students learn? Using the Learning and Study Process questionnaires (Education Paper No. 14). Hong Kong: University of Hong Kong, Faculty of Education.

[7] Coa. H. (2010). Urban-Rural Income Disparity and Urbanization: What Is the Role of Spatial Distribution of Ethnic Groups? A Case Study of Xinjiang Uyghur Autonomous Region in Western China Clevedon, UK: Multilingual Matters. Regional Studies, Vol. 44.8, pp. 965-982 DOI: 10.1080/00343400903401550.

[8] Deci, E.L. \& Ryan, R.M. (1985). Intrinsic motivation and self-determination in human behavior. New York: Plenum

[9] Dörnyei. Z. (1994). Motivation and Motivating in the Foreign Language Classroom. The Modern Language Journal, 78, pp 274-284

[10] Eccles, J. S \& Wigfield, A. (2002). Motivational beliefs, Values, and Goals. Annual. Review 53:109-132

[11] Eccles, J. S (2004). Schools, academic motivation, and stage-environment fit. In Handbook of Adolescent Psychology RM Lerner, L Steinberg (ed.), pp.125-53. Hoboken, NJ: Wiley. 2nd ed.

[12] Eccles, J. S. (2005). Subjective task value and the Eccles et al. model of achievement choices. Handbook of competence and motivation (pp.105-121). New York 
[13] Eric, T. S. (2007). 'Bilingual' education and discontent in Xinjiang. Central Asian Survey 26(2), 251-277 DOI: $10.1080 / 02634930701517482$.

[14] Feng. A \& Sunuodula. M. (2009). Analyzing language education policy for China's minority groups in its entirety. International Journal of Bilingual Education and Bilingualism, 12 (6), 685-704. http://dx.doi.org/10.1080/13670050802684396.

[15] Gardner, R. C (1985). Social Psychology and Second Language Learning: The role of attitudes and motivation. Edward Arnold, London.

[16] Gardner, R. C. (2001). Language Learning Motivation: The student, the teacher, and the researcher. Unpublished Keynote presentation at the Texas Foreign Language Education Conference, University of Texas at Austin

[17] Gao, Y., Zhao, Y., Cheng, Y., \& Zhou, Y. (2004). Motivation types of Chinese undergraduates. Asian Journal of English Language Teaching Vol.14 45-64.

[18] Hu. G. (2008). The Misleading Academic Discourse on Chinese-English Bilingual Education in China. Review of Educational Research June 2008, Vol. 78, No. 2, pp. 195-231 DOI: 10.3102/0034654307313406.

[19] Hu, G. (2005a). English language education in China: Policies, progress, and problems. Language Policy, 4 (1), 5-24. DOI: $10.1007 / \mathrm{s} 10993-004-6561-7$.

[20] Ibrahemi, A. (2003). A comparative study of language learning strategies employed by bilinguals and monolinguals with reference to attitudes and motivation. IJAL, Vo.6

[21] Kaplan, R. B. (2011). Macro language planning. In E. Hinkel (Ed.), Handbook of research in second language learning (Vol. II, pp. 924-935). New York: Routledge.

[22] Kaplan, R. B., \& Baldauf, R. B. Jr. (2003). Language planning: From practice to theory. Clevedon: Multilingual Matters.

[23] Jiang, Q., Liu Q., Quan, X \& Ma, C. (2007). EFL Education in Ethnic Minority Areas in Northwest China: An Investigational Study in Gansu Province. Feng (ed.) Bilingual Education in China: practices, policies and concepts. Multilingual Matters

[24] MOE. (2001, 2 号) (The Ministry of Education guidelines for vigorously promoting the teaching of English in primary schools). http://www.edu.cn/20010907/3000637.shtml.

[25] MOE. (2001, 4 号) (Guidelines on strengthening university undergraduate teaching and raising teaching standards). http://www.pgzx.edu.cn.

[26] MOE. (2007, 2 号) (Guidelines on further deepening educational reform of undergraduate teaching and strengthening educational quality). http://www.chinalawedu.com.

[27] Ma. R. (2007). A New Perspective in Guiding Ethnic Relations in the 21st Century: De-politization's of ethnicity in China. Asian Ethnicity, 8 (3): 199-217.

[28] Ma. R. (2009). Development of minority education and practice of bilingual education in Xinjiang Uyghur Autonomous Region. Front. Educ China 4(2): 188-251 DOI: 10.1007/s11516-009-0012-3.

[29] Masataka.O. (2008). 中国の少数民族教育之言語政策＼cjkstart社会評論社中 369 - 430

[30] Nunan. D. (2003). The impact of English as a global language on educational policies and practice in the Asia-Pacific Region. TESOL Quarterly, 37(4), 589-613.

[31] Ohki, M (2009). Stimuler la motivation de l'apprenant japonais de francais en contextualisant l'enseignment au Japon.

[32] Ojijed, W. (2010). Language Competition in an Ethnic Autonomous Region: A Case of Ethnic Mongol Students in Inner Mongolia. Chinese Education and Society, 43(1), 58-69.

[33] Pattanayak, P. D. (1990). Multilingualism in India. Multilingual Matters.

[34] Pintrich, P. R. (2003). A Motivational Science Perspective on the Role of Student Motivation in Learning and Teaching Contexts. Journal of Educational Psychology. 2003, Vol. 95, No. 4, 667-686 DOI:10.1037/0022-0663.95.4.667.

[35] Ryan, R. M \& Deci, E. L. (2000). Self-Determination Theory and the Facilitation of Intrinsic Motivation, Social Development, and Well-Being. American Psychologist. Vol. 55, No. 1, pp 68-78

[36] Rennninger, K.A. et al. \& Hidi, S. (2002). Students interest and achievement developmental issues raised by a case study. Development of achievement motivation (173-195). New York.

[37] Sunuodula. M \& Feng. A. (2011). Learning English as a third language by Uyghur students in Xinjiang: A blessing or disguise? Feng (ed.) English Language Education Across the greater China. Multilingual Matters

[38] Shaaban. K \& Ghaith. G. (2000). Student Motivation to Learn English as a Foreign Language. Foreign Language Annuals Vol.33, Issue.6, 632-644

[39] Viau, R. (2004). Learning difficulties, reference framework for intervention. Gouvernement du Québec Ministère de l'Éducation, 03-00866.

[40] Viau.R. (2000). The cross-cultural utility of constructs from American research in motivational studies with French-speaking students. American Association of Educational Research (AERA)

[41] Watkins, D., \& Ismail, M. (1994). Brief research report: Is the Asian learner a rote learner? A Malaysian perspective. Contemporary Educational Psychology, 19, 483-488.

[42] Wen, X. (1997). Motivation and Language Learning with Chinese. Foreign Language Annals

[43] Weiner B. 1985. An attributional theory of achievement motivation and emotion. Psychology. Rev. 92:548-73

[44] Wigfield. A. (1994). Expectancy-Value theory of Achievement Motivation: A Developmental Prospective Educational Psychology Review, Vol. 6, No.1.

[45] XUAR: http://uyghur.xjedu.gov.cn/zwgk/fzgy/2013/57028.htm.

[46] Yang, J. (2005). English as a Third Language among China's Ethnic Minorities. International Journal of Bilingual Education and Bilingualism, 8 (6), 552-567 DOI:10.1080/13670050508669068.

[47] Zhou, M. L. (ed.) (2004). Language policy in the People's Republic of China: Theory and practice since 1949. Boston: Kluwer Academic Publishers.

[48] Lee, J. \& Anderson, K.T. (2009). Opportunities and Risks in Education Negotiating Linguistic and Cultural Identities: Theorizing and Constructing. Review of Research in Education 33, 181-211. DOI: 10.3102/0091732X08327090. 
Rayhangül Ahåt is a lecturer of English at the Colleges of Foreign Languages, Xinjiang University, China. Her research interests mainly EFL teaching and learning in the context of English as an L3, including learner motivation, learner strategy and auton omous learning. She is also a Ph.D student of Kyoto University, Japan. 